\title{
SUICÍDIO NO MEIO RURAL: UMA REVISÃO INTEGRATIVA
}

\author{
SUICIDE IN THE COUNTRYSIDE: AN INTEGRATIVE REVIEW
}

SUICIDIO EN ÁREAS RURALES: UNA REVISIÓN INTEGRATIVA

\author{
Bruna Caroline Schoeninger ${ }^{1}$ \\ ORCID: https://orcid.org/0000-0001-5996-9404 \\ Márcia Luíza Pit Dal Magro ${ }^{2}$ \\ ORCID: https://orcid.org/0000-0002-2127-9261
}

Submissão: 20/12/2020/ Aceito: 15/03/2021 / Publicado 30/06/2021.

\begin{abstract}
Resumo
De acordo com a Organização Mundial da Saúde, o suicídio se configura como um sério problema de saúde pública, sendo que as mortes por suicídio têm aumentado nas últimas décadas. As mortes autoprovocadas também afetam os contextos rurais, que vem passando por transformações importantes nos modos de vida e trabalho. Este artigo teve como objetivo analisar como a produção científica publicada no período de 2013 a 2018 abordou o fenômeno do suicídio no meio rural. Para tanto, foi realizada revisão integrativa, a partir das bases de dados Google Acadêmico e Biblioteca Virtual de Saúde, tendo sido selecionados 16 artigos para análise. Foram elaboradas três categorias a partir dos resultados encontrados, que mostram os principais temas abordados pelos estudos, os quais são apresentados em diálogo com as discussões acerca do sofrimento social. O primeiro diz respeito à relação entre o uso de agrotóxicos e o suicídio, mencionado por 11 artigos. O segundo tema mais abordado foi o suicídio relacionado às transformações de vida e de produção no meio rural, que foi mencionado em 5 artigos. O último, se refere às características demográficas e étnicas nos contextos rurais, em que se destaca a relação entre suicídio, sexo e idade, e estudos que analisam a ocorrência de suicídios entre as etnias alemã e indígena. Conclui-se que os estudos dão ênfase a fatores de riscos específicos como o uso de agrotóxicos, tendo uma lacuna de estudos que integrem diferentes fatores de risco. Há ausência de estudos que tragam como ênfase modos de prevenção do suicídio nos contextos rurais.
\end{abstract}

Palavras-chave: Agricultor; Rural; Suicídio; Revisão integrativa.

\begin{abstract}
According to the World Health Organization (WHO), suicide means a serious public health problem nowadays, because in the last decades deaths by suicide have been increasing. Mortality by self-murderer also affects the rural landscape, whose been passing by meaningfully changes in their way of life and work. This article intends to assay how the scientific production published in Portuguese and Spanish language, during the period of 2013 to 2018, discuss the suicide

\footnotetext{
${ }^{1}$ Graduada em Psicologia pela Unochapecó, Psicóloga da APAE de Iporã do Oeste - SC. E-mail bruna.schoeninger@unochapeco.edu.br

${ }^{2}$ Mestre e Doutora em Psicologia pela UFSC. Professora do Programa de Pós-Graduação em Políticas Sociais e Dinâmicas Regionais e do Programa de Pós-Graduação em Educação da Unochapecó. E-mail mapit@unochapeco.edu.br
} DOI: http://dx.doi.org/10.22295/grifos.v30i23.5977 | Edição Vol. 30, Núm. 53, 2021.
\end{abstract}


phenomenon in the countryside. To do this, an integrative review has been made through the Google Scholar and Biblioteca Virtual de Saúde (BVS) data base, and selected 16 articles to be analyzed. Three categories were elaborated based on the results found, which show the main themes addressed by the studies, which are presented in dialogue with the discussions about social suffering. The first concerns the relationship between the use of pesticides and suicide, mentioned by 11 articles. The second most addressed topic was suicide related to changes in life and production in rural areas, which was mentioned in 5 articles. The last category talks about the demographic characteristics and ethnicity in the countryside, and highlight the relation that exists between suicide, sex and age, everything analyzed in studies about suicide in Germany and native ethnic group. In conclusion, the studies give emphasis to specifics risk factors, like the use of pesticides, but there is a gap in studies about other risk factors. Therefore, there are no studies that emphasize how to prevent suicide in rural landscape.

Keywords: Countryside; Integrative review; Suicide; Agriculturalist.

\section{Resumen}

Según la Organización Mundial de la Salud, el suicidio es un grave problema de salud pública y las muertes por suicidio han aumentado en las últimas décadas. Las muertes autoinfligidas también afectan los contextos rurales, que han experimentado importantes cambios en las formas de vida y trabajo. Este artículo tuvo como objetivo analizar cómo la producción científica publicada en el período de 2013 a 2018 abordó el fenómeno del suicidio en el medio rural. Para ello, se realizó una revisión integrativa, basada en dos bases de datos, a saber, Google Scholar y Virtual Health Library, con 16 artículos seleccionados para su análisis. Se elaboraron tres categorías a partir de los resultados encontrados, que muestran los principales temas abordados por los estudios. El primero se refiere al suicidio a la relación entre el uso de plaguicidas y el suicidio, mencionado por 11 artículos. El segundo tema más abordado fue el suicidio relacionado con cambios en la vida y la producción en las zonas rurales, que fue mencionado en 5 artículos. La última categoría se refiere a características demográficas y étnicas en contextos rurales, en los que destaca la relación entre suicidio, sexo y edad, y estudios que analizan la ocurrencia de suicidios entre etnias alemanas e indígenas. Se concluye que los estudios enfatizan factores de riesgo específicos como el uso de plaguicidas, con un vacío en los estudios que integran diferentes factores de riesgo. Hay una ausencia de estudios que enfaticen los métodos de prevención del suicidio en contextos rurales.

Palabras clave: agricultor; Rural; Suicidio; Revisión integrativa.

\section{INTRODUÇÃO}

De acordo com a Organização Pan-Americana da Saúde (OPAS), o suicídio se configura como um sério problema de saúde pública na atualidade, sendo responsável por aproximadamente 800 mil mortes por ano (OPAS, 2020). A agência aponta que a mortalidade decorrente de suicídios teve um aumento de $60 \%$ nos últimos 45 anos e, na maioria dos países, o suicídio figura entre as dez causas mais frequentes de mortalidade, sendo que entre a população jovem (de 15 e 29 anos) ela foi a segunda principal causa de morte em 2016 (OPAS, 2020).

Existem diferentes compreensões sobre as circunstâncias que motivam o suicídio, algumas concentram-se em fatores individuais e outras em aspectos sociais. A OMS (2014), na 
publicação do primeiro relatório sobre suicídio no mundo, traz que esse fenômeno estaria relacionado a um amplo espectro de fatores de risco, entre os quais estariam os fatores sociais, comunitários, relacionais e individuais. A OMS ainda afirma que as taxas de suicídio são muito diferentes de uma região para outra do globo, para o que serve de exemplo a diferença entre as Américas que apresentam uma taxa de suicídio de 6,1 por 100 mil habitantes, enquanto na Ásia essa é de 17,7 .

Werlang e Mendes (2013) trazem o sofrimento social como noção central para compreender o fenômeno do suicídio, sofrimento este que estaria relacionado à insatisfação das necessidades essenciais na vida dos sujeitos, sendo indissociável das noções de sofrimento psíquico e de sofrimento no trabalho. Para as autoras, a autodestruição deve ser pensada na relação com o sofrimento social decorrente de uma vulnerabilidade estrutural que nasce de exigências sociais e implica nas fragilidades individuais, em que há uma deterioração dos recursos sociais fundamentais para a luta contra as dificuldades da existência.

O sofrimento social está presente no meio rural, tendo como um de seus fatores o avanço capitalista que implica em novas formas de vida e de trabalho, as quais são geradoras de precariedade e de perda de objetos sociais (WERLANG, MENDES, 2013). Essa perda pode estar relacionada a aspectos individuais, sociais e culturais como dinheiro, status social, relações importantes, moradia, emprego, saúde, formas de lazer etc. De acordo com as autoras, as modificações pelas quais vem passando os territórios rurais estariam relacionadas à manifestação do suicídio nestes contextos.

O boletim epidemiológico de 2011 a 2016, do Ministério da Saúde, indica que 10,2\% das mortes por lesões autoprovocadas ocorreram em áreas rurais. No entanto, Gonçalves, Gonçalves e Oliveira Júnior (2011), ao avaliarem os determinantes socioeconômicos das taxas de suicídio por microrregiões brasileiras, concluem que há uma relação positiva entre o grau de ruralização e as taxas de suicídio. Isto, de acordo com os autores, indicaria "[...] que o difícil acesso à rede de saúde e de serviços em geral, o declínio econômico das áreas rurais e o uso de agrotóxicos, que desencadeiam quadros depressivos por mecanismos neurológicos ou endócrinos em lavradores, aumentam o risco de suicídio." (GONÇALVES; GONÇALVES; OLIVEIRA JÚNIOR, 2011, p. 307). De acordo com os autores, “[...] essa evidência empírica brasileira contraria a expectativa teórica, com base em Durkheim, na qual as taxas de suicídio são positivamente relacionadas com o grau de urbanização.” (GONÇALVES; GONÇALVES; OLIVEIRA JÚNIOR, 2011, p. 307).

A Organização Mundial da Saúde (WHO, 2006) indica o suicídio como um fenômeno que, com o passar das décadas, têm atraído a produção de estudos em diferentes perspectivas 
metodológicas, e de diferentes áreas de conhecimento. Dado à relevância do tema suicídio na atualidade, bem como sua manifestação nos contextos rurais em transformação, o presente estudo teve como objetivo analisar como a produção científica do período de 2013 a 2018, abordou o fenômeno do suicídio no meio rural.

\section{Método}

A presente pesquisa se pautou no método qualitativo, se caracterizando como uma revisão integrativa. Este método tem por objetivo a realização de um levantamento bibliográfico que tem como foco a compreensão sobre a produção científica acerca de um determinado tema, possibilitando a orientação de novas pesquisas e estudos. De acordo com Souza, Silva e Carvalho (2010, p. 102), a revisão integrativa é uma metodologia importante "[...] pois sintetiza as pesquisas disponíveis sobre determinada temática e direciona a prática fundamentando-se em conhecimento científico."

Na execução da revisão integrativa, foram utilizadas as fases definidas por Souza, Silva e Carvalho (2010), que são: 1) Elaboração da pergunta de pesquisa; 2) Busca na literatura; 3) Levantamento de informações; 4) Análise dos estudos incluídos e sistematização dos estudos encontrados; 5) Discussão dos resultados; 6) Apresentação da revisão integrativa.

A pesquisa foi realizada em duas bases de dados, sendo elas Google Acadêmico e Biblioteca Virtual de Saúde (BVS), sendo que as palavras-chaves utilizadas foram: "suicídio" or "lesões autoprovocadas" and "rural" or "agricultor" or "agricultura". Os critérios para a inclusão dos estudos foram: trabalhos publicados no formato de artigo científico; disponíveis na versão completa; nos idiomas português e/ou espanhol; publicados no período de 2013 a 2018, cujos objetivos e ou resultados e discussão estivessem relacionados ao tema deste estudo, que é o suicídio no contexto rural.

$\mathrm{Na}$ base de dados Google Acadêmico, com os critérios de inclusão adotados, foram encontrados 686 resultados, em relação aos quais foi feita a leitura do título e resumo. Após esta etapa, e excluindo os artigos repetidos, chegou-se a 37 artigos. Na Biblioteca Virtual de Saúde foram encontrados, na primeira etapa 680 resultados, e na segunda etapa obteve-se 37 resultados. Excluindo-se os artigos repetidos nas duas bases de dados e após a leitura dos artigos na íntegra, foram selecionados 16 artigos para análise.

\section{Caracterização dos artigos estudados e forma de análise}


Quanto aos métodos empregados para realizar os estudos, dos 16 artigos selecionados, cinco utilizam métodos de pesquisa quantitativos, dez artigos métodos qualitativos, e um artigo fez uso de metodologia mista. Dos cinco artigos de método quantitativo, três são pesquisas epidemiológicas, na qual o público-alvo em um são os idosos, em outro os indígenas e em outro os adolescentes. As diferentes metodologias empregadas demarcam distinções importantes para abordar a problemática do suicídio no meio rural, que aqui são analisadas tendo como noção principal o sofrimento social.

Quanto às regiões delimitadas nos estudos, nove artigos tiveram como foco de estudo a região Sul do Brasil, um o Nordeste, um o Centro-Oeste, um o Norte e dois delimitaram o Brasil, sem região específica. Dois artigos selecionados tiveram como foco outros países da América Latina, sendo um a região da Antioquia, na Colômbia, e um o Chile. Por fim, um artigo tinha como objeto a comparação de dados sobre o suicídio em três países, sendo eles China, França e Brasil.

A área de formação dos autores dos artigos escolhidos para este estudo, se concentram majoritariamente na área da saúde, sendo as formações de nove deles em Enfermagem, seis em Medicina, quatro em Psicologia, três das Ciências Biológicas e dois em Farmácia. Outra parte dos autores são formadas em áreas diversas sendo: dois da Engenharia Florestal, três das Ciências Sociais, dois da Agronomia e um da Filosofia, um da Medicina Veterinária e um do Serviço Social. As diferentes áreas de formação dos autores indicam que variadas áreas de conhecimento se detêm a estudar o fenômeno do suicídio. A seguir, estão listados os artigos selecionados para a pesquisa, 
Quadro 1 - Lista dos artigos selecionados

\begin{tabular}{|c|c|c|c|}
\hline $\mathrm{N}^{0}$ & ANO & TÍTULO & AUTORES \\
\hline 1 & 2013 & $\begin{array}{l}\text { Análise da letalidade decorrente de intoxicação por } \\
\text { agrotóxicos em agricultores da região sul do Brasil }\end{array}$ & $\begin{array}{l}\text { Kirchner; Silinske; Richter; } \\
\text { Chaves; Scherer; Benetti e } \\
\text { Stumm }\end{array}$ \\
\hline 2 & 2013 & $\begin{array}{l}\text { Intoxicações por agrotóxicos na mesorregião norte central } \\
\text { paranaense, Brasil - } 2002 \text { a } 2011\end{array}$ & Neves e Bellini \\
\hline 3 & 2013 & $\begin{array}{l}\text { Mortalidade por Suicídio: um enfoque em municípios com } \\
\text { alta proporção de população autodeclarada indígena no } \\
\text { Estado do Amazonas, Brasil }\end{array}$ & Orellana; Basta e Souza \\
\hline 4 & 2013 & $\begin{array}{l}\text { Paradoxos do desenvolvimento: agricultura química e } \\
\text { suicídios }\end{array}$ & Santos \\
\hline 5 & 2013 & $\begin{array}{l}\text { Suicídio de agricultores no Rio Grande do Norte: } \\
\text { compreensão fenomenológica preliminar dos aspectos } \\
\text { existenciais }\end{array}$ & Dutra e Roehe \\
\hline 6 & 2013 & $\begin{array}{l}\text { Um relato de vivência com agrotóxicos de um ex-trabalhador } \\
\text { rural: o papel social da ciência e da tecnologia e o ensino } \\
\text { de ciências }\end{array}$ & Genovese e Pessoa \\
\hline 7 & 2014 & $\begin{array}{l}\text { Muertes silenciadas: Problemática del suicidio en los } \\
\text { campesinos de La Unión (Antioquia) }\end{array}$ & Pérez \\
\hline 8 & 2014 & $\begin{array}{l}\text { Principal Causa de Mortalidade na População Adulta: } \\
\text { Municípios Produtores de Tabaco versus Urbanizados }\end{array}$ & $\begin{array}{l}\text { Ferraz; Kessler; Trindade e } \\
\text { Corralo }\end{array}$ \\
\hline 9 & 2015 & $\begin{array}{l}\text { Análise das intoxicações em idosos residentes na zona rural } \\
\text { de Campina Grande e região (2010-2014) }\end{array}$ & Coutinho; Mariz e Fook \\
\hline 10 & 2015 & $\begin{array}{l}\text { Da violência contra si: a autodestruição por meio do suicídio } \\
\text { no meio rural no Rio Grande do Sul/Brasil }\end{array}$ & Mendes e Werlang \\
\hline 11 & 2015 & $\begin{array}{l}\text { Prevalencia de intento de suicidio adolescente y factores de } \\
\text { riesgo asociados en una comuna rural de la provincia de } \\
\text { Concepción }\end{array}$ & $\begin{array}{l}\text { Valdivia; Silva; Sanhueza; } \\
\text { Cova e Melipillán }\end{array}$ \\
\hline 12 & 2017 & $\begin{array}{l}\text { Mortalidade por suicídio no Estado do Paraná segundo meios } \\
\text { utilizados: uma análise epidemiológica }\end{array}$ & $\begin{array}{l}\text { Rosa; Oliveira; Arruda e } \\
\text { Mathias }\end{array}$ \\
\hline 13 & 2018 & $\begin{array}{l}\text { Intoxicações e óbitos por agrotóxicos no Estado de Goiás, } \\
\text { Brasil e inovações legislativas }\end{array}$ & Tejerina \\
\hline 14 & 2018 & $\begin{array}{l}\text { Suicídio, cultura e trabalho em município de colonização } \\
\text { alemã no sul do Brasil }\end{array}$ & Meneghel e Moura \\
\hline 15 & 2018 & $\begin{array}{l}\text { Trabalho na agricultura: possível associação entre } \\
\text { intoxicação por agrotóxicos e depressão }\end{array}$ & $\begin{array}{l}\text { Gomes Filho Neto; Andrade } \\
\text { e Felden }\end{array}$ \\
\hline 16 & 2018 & $\begin{array}{l}\text { Legislação, Política Pública e Suicídio: A Influência do } \\
\text { Estado Sobre Vida e Morte de Agricultores Familiares }\end{array}$ & Drebes; Bohner e Silveira \\
\hline
\end{tabular}

Fonte: elaborado pelas autoras (2020).

Os artigos foram analisados com base na análise temática de conteúdo descrita por Minayo (2001), a qual pode ser elencada em três fases: 1) pré-análise, 2) exploração do material; 3) tratamento dos resultados, inferência e interpretação. Esta análise suscitou três categorias, que são: transformações de vida e de produção no meio rural; a relação entre o uso 
de agrotóxicos e o suicídio, e o suicídio relacionado às características demográficas e culturais nos contextos rurais.

\section{Compreensões sobre as causas do suicídio}

De acordo com OMS (2014), compreender o fenômeno do suicídio é algo complexo, que envolve distintos aspectos relacionados ao contexto social e comunitário, bem como a dimensão relacional e individual do sujeito que comete o ato. Esses diferentes aspectos se expressam como fatores de risco para as lesões autoprovocadas, entre os quais se destacam: a dificuldade de acesso aos serviços de saúde; o estigma associado ao sofrimento mental e à busca de ajuda para lidar com o mesmo; à facilidade de acesso a meios utilizados para o suicídio; a notificação inadequada de casos de suicídio pelos meios de comunicação. Também são destacados como fatores de risco: a exposição a situações de guerras, desastres e conflitos sociais; discriminação; imigração e aculturação; traumas e abusos; falta de apoio social; relações conflituosas; perda de pessoas significativas; perda de trabalho; uso crônico de álcool; dificuldades financeiras; transtornos mentais; dor crônica; antecedentes familiares de suicídio; fatores genéticos e biológicos.

De acordo com Werlang e Mendes (2013, p. 109), a história do sofrimento social entre os Séculos XVII e XX se trata da história da "dor das dores", que se refere à "experiência dolorosa de homens e mulheres que vivem no mundo social". Esta noção vem ganhando relevância em estudos de áreas como a sociologia e a psicologia, para entender a estreita relação entre as vulnerabilidades produzidas no campo social, e sua manifestação nas experiências de grupos e indivíduos, que tem como pano de fundo também a falta de amparo coletivo para lidar com essas vulnerabilidades (RENAULT, 2008).

Seria também uma experiência limitadora da condição humana e, como experiência social, poderia ser vista em pelo menos dois modos: como experiências coletivas apropriadas individualmente através de percepções e expressões e, também, como interações sociais trazidas através de experiências vinculadas a doenças que sugeririam relações e interações, ocupando, não raras vezes, lugar central na experiência do sofrimento. (WERLANG; MENDES, 2013, p. 110). 
Castel (1998) compreende o sofrimento como uma relação direta com os vínculos e integrações sociais, na qual os indivíduos estão inseridos em uma estrutura social, mas que não encontram seu lugar nela. Segundo Werlang e Mendes (2013), o sofrimento social precisa ser relacionado a uma sociedade com vulnerabilidade estrutural, na qual as fragilidades individuais nascem de exigências sociais de autonomia e realização.

[...] o sofrimento social brota, dessa situação paradoxal, resultante de uma autonomia obrigada ao indivíduo, sem suportes socialmente disponíveis. Como bem afirma Soulet, ao referir-se às expressões de sofrimento social, não importa se as formas extremas de sofrimento social, como o suicídio, se manifestam dentro dos teatros ou se exacerbam em um agir sobre o mundo, dentro da família ou no espaço do trabalho: ele se constitui em um efeito de nossa configuração social. (WERLANG; MENDES, 2013, p. 115).

As autoras apresentam que o centro de discussão do sofrimento social se daria por meio de uma deterioração das relações sociais que estão vinculadas às relações familiares, saúde, trabalho e lazer.

[...] o sofrimento social [...] se instala/esconde nas zonas de precariedade, nas zonas sociais de fragilidade e cuja ação implica na perda ou possibilidade dos objetos sociais: saúde, trabalho, desejos, sonhos, vínculos sociais, ou seja, o todo da vida composto pelo concreto e pelo subjetivo que permite viver a cada dia, a vida psíquica, a vida interior composta pela subjetividade. (WERLANG; MENDES, 2013, p. 227).

Castel (1998) aponta que a deterioração das relações tem vínculo com o contexto de uma precariedade psíquica que se dá por meio do "enfraquecimento do mundo", como uma maneira de não conseguir reconhecer a si mesmo como um indivíduo digno de uma existência grupal ou coletiva humana. Entende-se que o mundo deveria integrar os indivíduos como um modo de diminuir o sofrimento dos que fazem parte deste contexto. "A necessidade de não reconhecimento, da exclusão como uma forma de condenação social." (WERLANG; MENDES, 2013, p. 119).

Segundo Soulet (2009), independente se o suicídio se manifesta dentro da família ou no campo de trabalho, ele se constitui como efeito de uma configuração social que está relacionada às patologias sociais e na "invalidação dos dispositivos de formação e sustentação destes indivíduos no contexto social” (WERLANG; MENDES, 2013, p. 115).

Especificamente nos contextos rurais, a constituição do sofrimento social que leva ao suicídio estaria relacionada ao avanço capitalista nesses territórios. Werlang (2013) apontam que ocupar o espaço rural ou ser agricultor, na atualidade, é uma tarefa difícil, já que a 
precariedade decorrente do avanço capitalista no meio rural tem gerado sociopatologias, sofrimento social que têm levado ao suicídio. "Neste sentido, a morte por suicídio que atinge o meio rural é uma morte endereçada: alguém roubou as tortas, aqui identificadas como objetos sociais" (WERLANG, p. 228).

\title{
RESUlTADOS E DISCUSSÃO
}

\section{Transformações nos modos de produção e de vida no meio rural}

O acelerado processo de modificação nos modos de vida e produção no meio rural é uma realidade que afeta vários países. Dos artigos selecionados para este estudo, quatro deles dão ênfase a essas transformações quando analisam o fenômeno do suicídio, no entanto, outros onze trazem isso de forma implícita, por exemplo, ao abordar a relação entre o suicídio e o uso de agrotóxicos, os quais ensejam importante problemática dos atuais modos de produção no campo. Silva, Pasqualotto e Drebes (2016), apontam que, no Brasil, durante o Século XX, os agricultores passaram por intensas transformações nos seus modos de viver e exercer seu trabalho no meio rural, principalmente pela modernização da agricultura.

\begin{abstract}
Desde o final da década de 1940, com a instituição do serviço de Extensão Rural no Brasil, esses agricultores foram incentivados, através de crédito rural altamente subsidiado, a substituir os insumos utilizados em suas atividades, aderindo ao chamado 'pacote tecnológico'. Constituído por máquinas e implementos agrícolas, materiais de irrigação, sementes melhoradas, fertilizantes químicos e agrotóxicos, este pacote tecnológico, que embora tenha incrementado a produção e a produtividade da agricultura, desencadeou uma série de consequências negativas em termos econômicos, sociais e ambientais. (SILVA; PASQUALOTTO; DREBES, 2016, p. 83).
\end{abstract}

Segundo Andrades e Ganimi (2007), a Revolução Verde é o cenário de fundo que impulsiona essas mudanças e as problemáticas decorrentes das mesmas.

\footnotetext{
A Revolução Verde após ser inserida na agricultura do Brasil traz em seu seio inúmeras contradições. A promessa de emprego cai por terra, uma vez que as máquinas invadem o campo e a produção familiar diversificada passa a ser plantação de monocultura. $\mathrm{O}$ aumento da produção de alimentos para o mercado interno foi ínfimo, uma vez que os grandes campos de uma só cultura destinavamse à exportação. O êxodo rural pautado no desemprego facilitou a solidificação do latifúndio e o surgimento da periferia na zona urbana. $\mathrm{O}$ alimento orgânico dá
} 
espaço ao alimento sem segurança alimentar. A terra fértil passa por processos de desertificação. (LAZZARI; SOUZA, 2017, p. 05).

Mendes e Werlang (2015), no artigo 10, indicam que o capital investe para o fim da agricultura tradicional, isso se efetiva por meio da conexão com a indústria, da pluriatividade, da flexibilização e, ainda, pela precarização do trabalho no meio rural. A pluriatividade faz parte de um conjunto de transformações capitalistas no meio rural, que traz consequências, como a flexibilização, aumento da exploração e precarização das relações de trabalho.

Schneider (2003) destaca a precarização do trabalho e da vida no campo analisando a pluriatividade. Esta seria resultado da modernização tecnológica da agricultura, que impõe o uso de alta tecnologia no processo produtivo, deixando os processos de trabalho mais individualizados, causando uma significativa diminuição do uso da força de trabalho das famílias e a queda da renda. Nesse contexto, a contratação de máquinas e serviços de terceiros para a realização de atividades nas propriedades está crescendo significativamente, os agricultores tornaram-se dependentes da tecnologia e isso implica diretamente nos altos custos da produção agropecuária.

\footnotetext{
Portanto, pode-se dizer que a pluriatividade constitui-se em uma forma de acentuação da exploração capitalista nos interstícios da vida rural. Isto porque faz parte de um conjunto de transformações em curso que apontam para a flexibilização e a precarização das relações de trabalho, bem como para a reestruturação produtiva. (MENDES; WERLANG, 2016, p. 154).
}

Thiollent e Dorigon (2014), em seu estudo sobre as contribuições da autora francesa Salmona à saúde mental dos trabalhadores rurais, indicam que desde o período pós-guerra, a modernização da agricultura na França contribuiu para que fossem desenvolvidas práticas que ignoram a vida do trabalho. Essa modernização predominou em grande parte do mundo, inclusive no Brasil e nos países onde se desenvolveu a Revolução Verde, que tinha como objetivo o aumento da produtividade por meio do uso de novas tecnologias, maquinários, pesticidas e fertilizantes, quebrando as técnicas da agropecuária tradicional. Nesse contexto, haveria uma modificação do conhecimento tradicional dos agricultores para o da tecnociência. A partir da desapropriação do saber do trabalhador rural, entende-se que há uma perda de objetos sociais decorrente deste processo, que produz o sofrimento social, vivenciado na interioridade psíquica e expresso em atos como o suicídio.

Thiollent e Dorigon (2014) apontam que a adoção do conhecimento denominado algorítmico pelos agricultores, pode gerar um processo de culpabilização, pois estes são DOI: http://dx.doi.org/10.22295/grifos.v30i23.5977 | Edição Vol. 30, Núm. 53, 2021. 
convencidos pelas empresas agrícolas e seus instrutores de que os problemas são de fácil solução. No entanto, na prática, os problemas saem do campo do simples para o complexo, causando sentimentos de incapacidade e incompetência nos agricultores. Quanto mais os agricultores são capacitados para atividades sobre as quais esses já dispõem de numerosos conhecimentos práticos, mais eles têm a impressão de nada saberem e de que seus conhecimentos práticos são 'suspeitos' e não operacionais. (THIOLLENT; DORIGON, 2014, p. 380).

Segundo Thiollent e Dorigon (2014), nos últimos anos, em inúmeros países, as exigências empresariais, a precarização e intensificações do trabalho no meio rural estão ocasionando a deterioração de condições de vida, crises familiares, depressões e suicídios. Os autores indicam que o impacto das políticas públicas no âmbito econômico da agricultura coloca em evidência as patologias decorrentes da dificuldade de reorganização de rendimentos e investimentos do trabalho.

\begin{abstract}
Assim, os custos humanos ligados à modernização se referem ao empobrecimento das relações nos grupos familiares, e à dessocialização, que se produz pelo aumento da carga física e, sobretudo, pelo aumento da fadiga nervosa ligados às transformações e divisão do trabalho em função do gênero, ao aumento do tempo dedicado a atividades de supervisão, de controle e gestão técnica (THIOLLENT; DORIGON, 2014, p. 381).
\end{abstract}

O artigo 15, de Meneghel e Moura (2018, p. 06), aborda como as transformações imprimem novos modos de vida nos contextos rurais, “[...] a vida no campo deixou de ser aquela em que se produzia e se tinha tempo e autonomia. Cada vez mais, há interferências na vida do homem do campo e hoje o meio rural está pautado pelo urbano". Essas transformações para os para Silva, Pasqualoto e Drebes (2016), seriam o pano de fundo da problemática do suicídio no meio rural.

\begin{abstract}
Os suicídios não são somente estatísticas, mas também consistem em um símbolo das consternações vivenciadas nas áreas rurais. Talvez, constituam a mais medonha configuração das misérias desencadeadas das velozes, contínuas e incessantes transformações socioeconômicas incidentes sobre essas áreas, até recentemente idealizadas e reconhecidas como áreas 'serenas' e 'saudáveis'. (DREBES; PASQUALOTTO; SILVA, 2016, p. 82).
\end{abstract}

Segundo Werlang e Mendes (2016), os sujeitos pertencentes ao meio rural, para sobreviver, flexibilizam-se e precarizam as condições de trabalho para se adequar às indústrias agropecuárias. Essas exigências do capital indicam uma exploração no campo, que visa uma reestruturação produtiva, pois “[...] é preciso ampliar a margem de lucro e explorar 
cada vez mais o trabalho no mais longínquo dos espaços, sejam estes quais forem." (WERLANG; MENDES, 2016, p. 159). Nessa direção de análise, o artigo 10, de Mendes e Werlang (2015), aponta que as mortes autoprovocadas denunciam uma degradação dos modos de vida da população rural, atingindo a saúde mental desta população, causando inúmeros danos de alta gravidade.

O artigo 14, de Meneghel e Moura (2018), aponta que a maioria das pessoas que vive no meio rural trabalha nas atividades agrícolas, o que implica em um grande período de trabalho por parte de todos os integrantes da família, causando muitas vezes a ausência de diversão e contatos relacionados à vida social. Esse quadro, de modo intensificado, pode gerar depressão, ausência de perspectivas, quando há uma dificuldade financeira, e apatia, tendo muitas vezes como consequência o suicídio. Nessa direção, cabe destacar que Dejours e Begue (2010), que não centram seus estudos nos territórios rurais, afirmam a estreita relação entre a deterioração das relações de trabalho e o suicídio.

No artigo 5, Dutra e Roehe (2013) trazem uma entrevista realizada com um sujeito que vive no meio rural. Este sinaliza que existe uma dificuldade socioeconômica relativamente grande após a modernização agrícola e que muitos indivíduos não conseguem lidar com este fator, vendo no suicídio a única saída.

Considerando as mudanças que o avanço do capitalismo imprime aos territórios rurais, vários dos artigos analisados se detêm a mostrar um aumento no número de suicídios nestes contextos, o que pressupõe uma relação desse ato-dor ${ }^{3}$ (MACEDO, WERLANG, 2007) que denuncia um intenso sofrimento psíquico frente a um sofrimento social engendrado nos contextos rurais.

\section{A relação entre o uso de agrotóxico e o suicídio}

Na revisão integrativa aqui apresentada, dos 16 artigos, 11 deles mencionam a relação entre o uso de agrotóxicos e o suicídio no meio rural, transformando esta na categoria mais recorrente nos estudos analisados. Dos 11 artigos que trazem esta discussão, oito tem como

\footnotetext{
${ }^{3} \mathrm{O}$ ato-dor destacado pelos autores, se remete à tentativa de suicídio como uma expressão da força de um conteúdo traumático, em que a violência auto-infringida é provocada pela dor psíquica oriunda deste (MACEDO, WERLANG, 2007). 
foco a relação entre intoxicação, adoecimento mental e suicídio, e três destacam o agrotóxico como meio utilizado para realizar o suicídio, através da ingestão destas substâncias.

Os autores Santos, Legay e Lovisi (2013), em seu estudo, trazem o termo intoxicação exógena como um meio utilizado para o suicídio. As principais substâncias utilizadas para este método de autodestruição são os agrotóxicos. No Brasil, a intoxicação exógena corresponde a 70\% dos casos de suicídio notificados. Durante o período de 1998 a 2009 , houve 112.295 internações devido a tentativas de suicídio utilizando o método de ingestão de substâncias tóxicas, sendo $15,1 \%$ destes a intoxicação por pesticidas.

\footnotetext{
Os autores também argumentam que, tendo os impulsos suicidas geralmente uma curta duração, dificultar o acesso ou reduzir os aspectos mais letais dos meios que são utilizados podem reduzir uma importante proporção desses agravos. [..] foi através da restrição de agrotóxicos classe I (extremamente tóxico) que ocorreu o declínio das taxas de suicídio. (SANTOS; LEGAY; LOVISI, 2013, p. 58).
}

O artigo 7, de Pérez (2014), tem como foco a problemática do suicídio em camponeses da Antioquia (Colômbia), e conclui que a facilidade do acesso aos produtos de alta toxicidade é um fator de risco para as mortes voluntárias, mais especificamente o suicídio. O autor nomeia este fator como uma "estrutura de oportunidades", onde os casos de suicídio têm o risco elevado em populações camponesas que estão expostas a produtos altamente tóxicos e letais.

De acordo com o artigo 2, para Neves e Bellini (2013), a letalidade ocasionada pelos agrotóxicos pode ser dividida em possibilidade de exposição ocupacional, acidental e exposições intencionais. A exposição ocupacional refere-se ao grupo de indivíduos que tem contato direto com os agrotóxicos, principalmente os agricultores. Esta intoxicação pode ocorrer principalmente durante o processo de aplicação dos agrotóxicos. Logo, a exposição acidental tem relação com os agrotóxicos presentes em ambientes domésticos, exposições que ocorrem geralmente pelo armazenamento inadequado e, ainda, pela ingestão involuntária de alimentos contaminados.

Ao encontro do que apontam os artigos anteriormente citados, a Organização Mundial de Saúde (2014) aponta que a ingestão de pesticidas se refere a um terço dos suicídios do mundo. Estes números são registrados principalmente em zonas rurais de países considerados de baixa renda. Estes dados indicam que o acesso a esses produtos tóxicos se caracteriza como um fator de risco que aumenta a probabilidade da ocorrência desses eventos nos espaços rurais. 
Já a outra parte dos artigos analisados dá ênfase à relação entre intoxicação e uso de agrotóxicos. Esse uso começa na década de 1940, com a Revolução Verde, que encontra no uso dessas substâncias uma forma de aumentar a produção agrícola. Este aumento também se efetiva por meio do desenvolvimento de pesquisas em sementes específicas para determinados solos e climas, processo de fertilização do solo e mecanização de processos até então manuais. (FRANCISCO, 2019).

As sementes que são desenvolvidas e modificadas nos laboratórios são resistentes a inúmeros tipos de pragas e doenças e estão diretamente associadas aos agrotóxicos. De acordo com Alencar e Pedro (2019), pesquisas feitas pela Agência Nacional de Vigilância Sanitária (Anvisa) apontam o Brasil como campeão mundial no uso de agrotóxicos desde 2008. Em 2012, o país comprou mais de 800 mil toneladas de agrotóxicos, entre os quais muitos estão proibidos em outros países. Segundo Lopes e Albuquerque (2018), na última década, o Brasil expandiu 190\% o mercado de agrotóxicos.

Uma parte dos estudos realizados afirma a relação entre uso de agrotóxicos e a ocorrência de suicídios, por meio da reflexão sobre a ampliação do uso dessas substâncias no meio rural. Os artigos 1, 4 e 13 destacam os impactos dos agrotóxicos na saúde humana, e, especificamente, nos indivíduos que vivem no meio rural e que têm contato mais direto com essas substâncias.

Segundo o artigo 16, de Drebes, Bohner e Silveira (2018), o uso exacerbado de agrotóxicos no sistema agrícola está impactando diretamente na saúde da população rural, principalmente no grande número de suicídios que estão inseridos neste contexto. No artigo 4, um estudo realizado no Rio Grande do Sul, Santos (2013) aponta que os índices de suicídio decorrentes do uso de agrotóxicos chegam a 37,22 por 100.000 habitantes. O autor também aponta dados de uma cidade do extremo oeste do mesmo estado, na qual, em 2004, ocorreram 33 casos de suicídio no meio rural.

Alguns estudos analisados, como no artigo 15, estabelecem uma relação do suicídio com os danos neurológicos provocados por agrotóxicos específicos, entre os quais se destacam os organofosforados. A grande variedade de agrotóxicos existentes no mercado estaria diretamente relacionada ao descontrole do uso destas substâncias. Segundo Gomes Filho Neto, Andrade e Felden (2018, p. 78), do artigo 15, “[...] os resultados indicam que os agricultores que trabalham expostos com organofosforados são propensos a distúrbios 
neuropsicológicos e que quanto maior tempo de exposição aos produtos tóxicos, maiores são os sintomas clínicos."

No artigo 16, Drebes Bohner e Silveira (2018) apresentam em sua análise que em 49,7\% dos casos de suicídio os indivíduos sofriam algum tipo de transtorno mental. O que foi apontado pelos artigos 15 e 16 sobre, é reiterado por outros autores como Hess (2018), que aponta que a intoxicação por agrotóxicos produz problemas de desenvolvimento, aprendizagem, alterações do comportamento e transtornos mentais.

[...] expostos repetidamente a estas substâncias podem apresentar memória prejudicada e perda de concentração, depressão grave e psicose aguda, irritabilidade, confusão, apatia, labilidade emocional, dificuldades de fala, dor de cabeça, desorientação espacial, tempos de reação atrasadas, sonambulismo, sonolência ou insônia. (HESS, 2018, p. 141).

Segundo Morin e Stumm (2018), a exposição a agrotóxicos torna-se responsável por sintomas físicos e emocionais. Os danos à saúde mental ressaltam-se nesse contexto, as queixas baseiam-se em sintomas depressivos, de ansiedade, de insônia, irritabilidade e fadiga.

\footnotetext{
Investigação em população rural do Sul do Brasil avaliou associação entre contato com agrotóxicos e prevalência de doenças crônicas em 298 pessoas que exerciam atividades rurais ou eram membros de famílias de agricultores. Os resultados revelaram que o contato direto ou indireto com agrotóxicos associa-se ao relato de várias doenças, sendo as neurológicas e as orais as mais prevalentes. (MORIN; STUMM, 2018, p. 202).
}

Santos (2013), do artigo 4, indica que há uma constante modificação toxicológica dos agrotóxicos que são utilizados no Brasil, o que acaba acarretando uma confusão por parte dos agricultores, pois os mesmos acabam se desapropriando das informações necessárias de utilização e isso interfere na maneira com que utilizam os agrotóxicos, acarretando no uso impróprio dos produtos, a alta toxicidade, a não utilização de equipamentos de proteção e, ainda, a precariedade da vigilância.

Dos agrotóxicos utilizados no Brasil, que transformou produtos antes classificados como extremamente tóxicos (faixa vermelha) e altamente tóxicos (faixa amarela) em medianamente tóxicos (faixa azul) e pouco tóxicos (faixa verde). Essa reclassificação contínua ocorreu 5 vezes no período de 1978 a 1998). (SANTOS, 2013, p. 112, [artigo 4]).

Os agrotóxicos utilizados nas produções agrícolas, em sua maioria, são manuseados por todos os integrantes da família sem muitas restrições. Coutinho, Mariz e Fook (2015), 
no artigo 9, fazem uma relação do suicídio no meio rural, indicando a exposição dos agrotóxicos e a população idosa. Segundo os autores, estudos realizados na zona rural de Campina Grande do estado da Paraíba, apontam que o nível de escolaridade é um fator determinante para o caso de exposições a produtos tóxicos utilizados pelo homem do campo. No entanto, 88,2 \% dos casos de intoxicações, ocorreram em residências de idosos. Os autores ainda indicam que o suicídio de idosos por envenenamento representa $18,7 \%$ do total de casos de morte no Nordeste brasileiro.

A partir da análise dos artigos, observa-se que a presença massiva dos agrotóxicos nos contextos rurais, são fruto das transformações nos modos de produção e trabalho, que marcam novas vulnerabilidades e sofrimentos sociais. Os agrotóxicos caracterizam um risco laboral importante, que tem relação com diversos problemas de saúde, tendo no suicídio uma de suas expressões mais dramáticas.

\section{O suicídio relacionado às características demográficas e étnicas nos contextos rurais}

As características demográficas e culturais como sexo, idade e etnia são também fatores destacados na análise do suicídio no meio rural por onze dos artigos analisados.

Em relação a variável demográfica sexo, historicamente se apresentou que a taxa de suicídios entre homens é maior que entre mulheres. Isso vai ao encontro do que apresenta a OMS (2014), que indica que a taxa de suicídio entre homens é de $57 \%$ enquanto a taxa de suicídios entre mulheres é de 43\%, o que também é apresentado pelos artigos 5, 14 e 18 . No entanto, a agência destaca que esses índices apresentam grandes diferenças entre as regiões e os países. A explicação para a diferença entre a taxa de suicídios entre os sexos estaria relacionada a questões como métodos sociais aceitáveis para abordar os conflitos e o estresse, taxas de busca de atenção para os transtornos mentais, entre outros (OMS, 2014).

Segundo Drebes, Bohner e Silveira (2018), do artigo 16, foi realizada uma avaliação dos casos de tentativas de suicídio e houve a conclusão de que 40,2\% dos suicídios na região central da China foram praticados por mulheres residentes no meio rural, que, em sua maioria, participavam das atividades da agricultura. Dutra e Roehe (2013), do artigo 5, indicam que sujeitos do sexo masculino cometem mais suicídio do que os do sexo feminino, no entanto, são as mulheres que mais tentam o suicídio, o que estaria relacionado especialmente à sobrecarga de trabalho e ao sofrimento psíquico oriundo desta. 
[...] a perda do trabalho para as mulheres não é importante porque elas passam a trabalhar como faxineiras', porém, na agricultura, a divisão sexual do trabalho significa que, além do cuidado da casa, dos filhos, da horta, dos animais domésticos, elas precisam auxiliar em todas as etapas do cultivo. [..] e a sobrecarga pela dupla função de agricultoras e donas de casa produz adoecimento, mal-estar e até suicídio, mesmo em menores proporções que os homens. (MENEGHEL; MOURA, 2018, p. 05, [artigo 14]).

De acordo com Pérez (2014), no artigo 7, em um estudo sobre o suicídio na Colômbia, também há destaque para a presença deste fenômeno em uma faixa etária específica. Nesse sentido, o referido estudo indica que os jovens são os novos "protagonistas" do suicídio. Atualmente, segundo a OMS, o suicídio está entre as três principais causas de morte entre os indivíduos de 15 a 35 anos de idade.

\begin{abstract}
Esta tendencia a nivel global también fue evidente en el municipio estudiado, con algunas singularidades. En La Unión, la mayor cantidad de suicidios se presenta en franjas de edades jóvenes, esto es, de quince a veinticuatro años $(32,89 \%)$ y de veinticinco a treinta y cinco $(26,32 \%)$, quienes concentran la mitad de la población suicida de esta localidad (figura 2). Igualmente, el grupo de adultos entre treinta y cinco y cuarenta y cuatro años también es importante $(21,05 \%)$, mientras que en edades más avanzadas (mayores de cuarenta y cuatro años) decrece significativamente el número de suicidios (14,47\%). (PÉREZ, 2014, p. 96, [artigo 7]).
\end{abstract}

Outros dois artigos analisados fazem relação entre etnia e suicídio, sendo eles os artigos 3 e 14. No artigo 14, Meneghel e Moura (2018) que recorrem a análise de Durkheim sobre o suicídio como expressão de uma questão social, analisam o suicídio como um recurso presente na cultura alemã para enfrentar as dificuldades.

Então, é preciso entender que elementos velhos e novos misturados influenciaram a visão de mundo desses alemães no Brasil; e como essa visão pode ajudar ou não nos embates frente aos novos processos de exploração do trabalho rural, com que se defrontam na atualidade. (MENEGHEL; MOURA, 2018, p. 05, [artigo 14]).

Considerando que cidades com prevalência de colonização alemã apresentam maiores índices de suicídio, as autoras indicam que um dos determinantes do suicídio referese à influência da ética do trabalho na cultura de origem germânica. Em uma narrativa apresentada durante o artigo de Meneghel e Moura (2018), reforça-se a rigidez do comportamento alemão.

[...] antigamente, no meio rural se falava muito em 'nervenkrankheit' que em alemão quer dizer doença dos nervos. Isso parece reforçar a questão cultural, talvez os de origem germânica sejam mais exigentes consigo mesmos, possivelmente os 
luteranos se cobrem mais. Algo na cultura dos alemães faz com que o índice de suicídio seja mais elevado, comparando com cidades de origem portuguesa. (MENEGHEL; MOURA, 2018, p. 04, [artigo 14]).

As autoras do artigo 14 fazem essa relação com os alemães e o suicídio indicando essa dificuldade cultural em aceitar o fracasso econômico, fator este que pode ter relação direta com uma cultura de honra masculina, trazida no estudo do artigo 15. A masculinidade nas sociedades rurais tem vínculo com o estereótipo de homem que é idealizado, homem provedor e chefe da família que têm o "dever” de sustentar a casa. Logo, quando há o fracasso socioeconômico, é o homem que se responsabiliza.

Já no artigo 3, Orellana, Basta e Souza (2013) discutem o suicídio em outras etnias, que remetem aos povos originários. De acordo com este estudo, nas populações indígenas, tanto no Brasil como na América do Norte e na Oceania, são mais frequentes os suicídios entre a população jovem, indicando maior prevalência deste fenômeno em uma faixa etária específica.

Os mesmos autores, apontam ainda que em contextos indígenas dos Estados Unidos, no Canadá, na Austrália e na Nova Zelândia, os suicídios estão associados principalmente a “[...] fatores biológicos, a questões relacionadas ao acesso, qualidade dos serviços ofertados à população, e a aspectos particulares da organização sociocultural dos grupos estudados." (ORELLANA; BASTA; SOUZA, 2013, p. 666).

\begin{abstract}
No que diz respeito aos aspectos socioculturais, não se pode ignorar o fato de que o fenômeno do suicídio entre povos indígenas é complexo e multimediado. Aho e Liu demarcam a possível influência deletéria do conjunto de violências sofridas durante o extenso processo de colonização na maior ou menor ocorrência de suicídio entre populações nativas. Hunter et al. E Silviken chamam a atenção para a importância do modo como os indígenas, ao longo do tempo, lidam também com as assimétricas relações estabelecidas com a sociedade não indígena para compreensão do suicídio. (ORELLANA; BASTA; SOUZA, 2013, p. 666, [artigo 3]).
\end{abstract}

No artigo 3, Orellana, Basta e Souza (2013) indicam que não há uma conclusão específica das motivações que levam os indígenas a cometerem suicídio, porém, a partir de pesquisas realizadas em países europeus e da América do Norte, os transtornos mentais aparecem com grande proporção entre as vítimas de suicídio.

De acordo com o Martins (2019) o Conselho Indigenista Missionário (CIMI) indicou que o número de suicídios entre indígenas aumentou 20\% em um ano. Em 2017, foram registradas 128 mortes por suicídio entre etnias indígenas. De acordo com o autor, as motivações para a violência auto-infringida estariam relacionadas principalmente a falta de 
acesso a políticas públicas, meios de lazer e de trabalho. Essa realidade mobilizaria junto a essas etnias a desesperança e falta sentimento de pertença. Estes fatores articulam-se diretamente com a noção de sofrimento social na medida em que indicam uma perda de objetos sociais e individuais nas motivações apresentadas, indicando que há uma dominação imposta do mundo capitalista frente aos povos originários. Esta relação de sofrimento social e de não pertencimento também se relaciona a etnia alemã por exemplo, onde os sujeitos que se deparam com a falência, fracasso econômico, sentem-se desvinculados de uma cultura, uma maneira de viver que sempre lhes pertenceu.

\section{CONSIDERAÇÕES FINAIS}

A partir dos artigos estudados, foi possível tecer um panorama sobre a maneira como a produção científica vem abordando a problemática do suicídio no meio rural. As categorias presentes neste estudo apresentam as principais causas do suicídio no meio rural identificadas pela literatura científica analisada. O uso de agrotóxicos no contexto rural esteve presente em um grande número de estudos encontrados, indicando que a Revolução Verde e as exigências das indústrias agropecuárias implicam aumento significativo no uso dessas substâncias com o intuito de aumentar a produção no campo e, assim, gerar mais lucros. No entanto, esse aumento resulta em um uso exacerbado de produtos tóxicos, os quais geram intoxicações involuntárias e voluntárias, e impactam na saúde mental dos sujeitos pertencentes ao meio rural, podendo resultar no suicídio.

As exigências da indústria agropecuária têm relação estreita com as transformações dos modos de produção e de vida no meio rural, outro tema que teve destaque na literatura científica analisada. Essa sugere que os produtores rurais acabam tendo que se adequar às mudanças impostas, como o implemento de tecnologias de ponta no uso de máquinas e sementes. Neste contexto, aumenta a concentração de renda, o êxodo rural, precariza-se o trabalho e vida no campo, o que levaria ao suicídio.

O suicídio relacionado às características demográficas nos contextos rurais, aponta a prevalência do suicídio entre os homens e entre os jovens, bem como a prevalência de tentativas de suicídio entre as mulheres. Já no que diz respeito à etnia, os estudos destacam as relações culturais e o suicídio entre alemães e também povos originários. 
Destaca-se que todas essas categorias presentes na produção científica analisada, podem ser relacionadas ao sofrimento social, tendo em vista a relação deste sofrimento com a precariedade da vida e com a perda de objetos sociais que fazem o sujeito se sentir excluído de um coletivo, demarcando processos de desfiliação social.

Ao final do processo de análise, destaca-se como um limite a exclusão de artigos publicados em língua inglesa. Também conclui-se que os estudos sobre o tema do suicídio rural enfatizam determinados riscos como a etnia, mas acabam excluindo outros. Mesmo focando-se em aspectos específicos como os agrotóxicos, ou bastante amplos como as transformações nos modos de vida rural, as conclusões apresentadas são abertas, indicando a necessidade de se trazer para a discussão a complexidade do fenômeno em questão. Nesse sentido, sugerem-se estudos que consigam ampliar os fatores de risco analisados frente ao suicídio, e que mesclem metodologias qualitativas e quantitativas a fim de ampliarem as variáveis de análise.

Também se observou a falta de pesquisas relacionadas a prevenção do suicídio no meio rural, em relação ao que se sugere estudos. Esses podem subsidiar a elaboração de políticas públicas e ações da sociedade civil no enfrentamento da problemática.

\section{REFERÊNCIAS}

ALENCAR, Ana; PEDRO, Antonio Fernando Pinheiro. Brasil, campeão no uso de agrotóxicos. 05 maio 2019. Disponível em: <http://www.ambientelegal.com.br/brasil-campeao-no-uso-de-agrotoxicos/>. Acesso em: 03 jun. 2019.

ANDRADES, Thiago Oliveira de; GANIMI, Rosângela Nasser. Revolução verde e apropriação capitalista. CES Revista, Juiz de Fora, v.21, p. 43-56, 2007.

CASTEL, Robert. As metamorfoses da questão social: uma crônica do salário. Petrópolis: Vozes, 1998.

DEJOURS, Cristophe; FLORENCE, Bègue. Suicídio e trabalho: o que fazer? Brasília: Paralelo 15, 2010. 128 p.

FRANCISCO, W. D. Revolução Verde. 05 maio 2019. Disponível em: <https://brasilescola.uol.com.br/geografia/revolucao-verde.htm>. Acesso em: 10 jun. 2019. 
GONÇALVES, Ludmilla R; GONÇALVES, Eduardo; OLIVEIRA JÚNIOR, Lourival Batista de. Determinantes espaciais e socioeconômicos do suicídio no Brasil: uma abordagem regional. Nova econ., Belo Horizonte, v. 21, n. 2, maio/ago. 2011.

HESS, Sonia Corina (Org.). Ensaios sobre poluição e doenças no Brasil. 1. ed. São Paulo: Outras Expressões, 2018. 344 p.

LAZZARI, Francini Meneghini; SOUZA, Andressa Silva. Revolução verde: impactos sobre os conhecimentos tradicionais. In: CONGRESSO INTERNACIONAL DE DIREITO E CONTEMPORANEIDADE, Santa Maria, Universidade Federal de Santa Maria (UFSM), Anais..., 8-10 nov. 2017.

LOPES, Carla Vanessa Alves; ALBUQUERQUE, Guilherme Souza Cavalcanti de. Agrotóxicos e seus impactos na saúde humana e ambiental: uma revisão sistemática. Saúde Debate [online], Rio de Janeiro, v. 42, n. 117, p. 518-534, 2018.

MACEDO, Mônica Medeiros Kother; WERLANG, Blanca Susana Guevara. Tentativa de suicídio: o traumático via ato-dor. Psicologia: Teoria e Pesquisa. v. 23, n. 2, p. 185-194, 2007.

MARTINS, F. O suicídio do povo indígena. [s.d.]. Disponível em: <https://www.cvv.org.br/blog/o-suicidio-do-povo-indigena/>. Acesso em: 26 jun. 2019.

MINAYO, M. C. S. (Org.). Pesquisa social: teoria, método e criatividade. Rio de Janeiro: Vozes, 2001.

MORIN, Pâmela Vione; STUMM, Eniva Miladi Fernandes. Transtornos mentais comuns em agricultores, relação com agrotóxicos, sintomas físicos e doenças preexistentes. Psico, Porto Alegre, v. 49, n. 2, 2018.

OPAS BRASIL. Folha informativa - Suicídio. Agosto de 2020. Disponível em: $<$ https://www.paho.org/bra/index.php?option=com_content $\&$ view $=$ article \&id=5671: fol ha-informativa-suicidio\&Itemid=839>. Acesso em: $22 \mathrm{dez}$. de 2020.

OMS, Organización Mundial de la Salud. Prevención del suicidio: un imperativo global. Washington, DC: OPS, 2014. Disponível em: < https://apps.who.int/iris/bitstream/handle/10665/136083/9789275318508_spa.pdf;jsessionid= F6D5521F104E887836EBCD61AF0F3C96? sequence=1>. Acesso em: 20 jun. de 2019.

RENAULT, Emanuel. Souffrances sociales. Paris: La Découverte, 2008.

SANTOS, Simone Agadir; LEGAY, Letícia Fortes; LOVISI, Giovanni Marcos. Substâncias tóxicas e tentativas e suicídios: considerações sobre acesso e medidas restritivas. Cad. saúde. colet., Rio de Janeiro, v. 21, n. 1, p. 53-61, 2013.

SCHNEIDER, Sérgio. Teoria social, agricultura familiar e pluriatividade. Rev. bras. Ci. Soc. [online], São Paulo, v. 18, n. 51, p. 99-122, 2003. 
SOULET, Marc-Henry. La souffrance sociale, pathologie des sociétés contemporaines. Étique publique, v. 11, n. 2, 2009.

SOUZA, Marcela Tavares de; SILVA, Michelly Dias da; CARVALHO, Rachel de. Revisão integrativa: o que é e como fazer. Einstein, 2010.

THIOLLENT, Michel Jean-Marie; DORIGON, Clovis. Estudo das condições de vida, trabalho e saúde de produtores rurais: a contribuição de Michèle Salmona. Organizações Rurais \& Agroindustriais, Minas Gerais, v. 16, n. 3, p. 376-387, 2014.

WERLANG, Rosangela. Pra que mexer nisso? Suicídio e sofrimento social no meio rural. Doutorado em psicologia social e institucional. Tese (Doutorado em Psicologia Social e Institucional) - Universidade Federal do Rio Grande do Sul (UFRGS), Porto Alegre, 2013.

WERLANG, Rosangela; MENDES, Jussara Maria Rosa. Pluriatividade no meio rural: flexibilização e precarização do trabalho na agricultura familiar. Em Pauta, Rio de Janeiro, v. 14, n. 38, p. 140-163, jul. 2016.

WERLANG, Rosangela; MENDES, Jussara Maria Rosa. Sofrimento social. Serv. Soc. Soc., São Paulo, n. 116, p. 743-768, out./dez. 2013.

WHO - World Health Organization. Prevenção do suicídio um recurso para conselheiros. Genebra: WHO, 2006. Disponível em: <http://www.who.int/mental_health/media/counsellors_portuguese.pdf $>$. Acesso em: 20 jun.

2019. 